\title{
Inhibition of the Pentose-phosphate Pathway Selectively Sensitizes Leukemia Lymphocytes to Chemotherapeutics by ROS-independent Mechanism
}

\author{
ZHIVKO ZHELEV ${ }^{1,2}$, DONIKA IVANOVA ${ }^{1}$, RUMIANA BAKALOVA $^{3,4^{*}}$, ICHIO AOKI $^{3}$ and TATSUYA HIGASHI ${ }^{3}$ \\ ${ }^{1}$ Medical Faculty, Trakia University, Stara Zagora, Bulgaria; \\ ${ }^{2}$ Institute of Biophysics \& Biomedical Engineering, Bulgarian Academy of Sciences, Sofia, Bulgaria; \\ ${ }^{3}$ Department of Molecular Imaging and Theranostics, National Institute of Radiological Sciences, \\ National Institute for Quantum and Radiological Science and Technology, Chiba, Japan; \\ ${ }^{4}$ Medical Faculty, Sofia University "St. Kliment Ohridski”, Sofia, Bulgaria
}

\begin{abstract}
The aim of the present study was to investigate: (i) the possibility of sensitizing leukemia lymphocytes to anticancer drugs by inhibiting pentose-phosphate pathway using 6-aminonicotinamide (6-ANA); (ii) to find combinations with synergistic cytotoxic effect on leukemia lymphocytes and to investigate their cytotoxicity towards normal lymphocytes; (iii) and to clarify the role of reactive oxygen species (ROS) in the induction of apoptosis by those combinations. The study covers 15 anticancer drugs - conventional and newgeneration. The experiments were performed on Jurkat leukemia cell line and normal lymphocytes, isolated from clinically healthy blood donors. Four parameters were analyzed simultaneously in both cell suspensions treated by drug or 6-ANA (separately, and in combination): cell viability, induction of apoptosis, level of ROS, and level of protein-carbonyl products. Most combinations of drug plus 6-ANA were characterized by synergistic cytotoxic effects on Jurkat cells. The synergism increased with increasing incubation time. Upon combination of 6-ANA with conventional chemotherapeutic (e.g. doxorubicin), synergistic cytotoxic effects were also detected in normal lymphocytes. In both cell types, the cytotoxicity of the combination of doxorubicin plus 6-ANA was accompanied by increased induction of apoptosis, but by a slight reduction of ROS and
\end{abstract}

Correspondence to: Rumiana Bakalova, Ph.D., DSci, Department of Molecular Imaging and Theranostics, National Institute of Radiological Sciences (NIRS), National Institute for Quantum and Radiological Science and Technology (QST), 4-9-1 Anagawa, Inageku, Chiba 263-8555, Japan. E-mail: bakalova.rumiana@qst.go.jp

Key Words: 6-Aminonicotinamide, leukemia lymphocytes, ROS, chemotherapeutics. protein-carbonyl products compared to cells treated with doxorubicin only. Upon combination of 6-ANA with newgeneration anticancer drugs (e.g. everolimus or barasertib), the synergistic cytotoxic effect on leukemia lymphocytes was also accompanied by very strong induction of apoptosis through ROS-independent mechanism(s). Neither of these combinations exhibited any cytotoxicity towards normal lymphocytes. The data suggest that 6-ANA could be used as a supplementary component in anticancer chemotherapy, and would allows therapeutic doses of anticancer drugs to be reduced, thereby minimizing their side-effects.

Many studies have demonstrated that anthracyclines, widely used to treat various malignant tumors, increase intracellular generation of reactive oxygen species (ROS) and alter cellular redox homeostasis (1-10). For example, the antitumor activity of one of the most effective anthracycline antibiotics, doxorubicin, is due to DNA damage, mainly through inhibition of DNA topoisomerase II enzyme after induction of double-strand DNA breaks (11). However, doxorubicin is localized in mitochondria and is highly susceptible to enzymatic reactions with generation of ROS and products of free radical oxidation, which can cause mitochondrial swelling, ultrastructural changes and alteration of mitochondrial function $(12,13)$. Doxorubicin-induced oxidative stress causes depolarization of the mitochondrial membrane, which leads to apoptosis. Another widely used anthracycline, cisplatin, interacts with nucleophilic N7 sites of purine bases in DNA, leading to formation of DNAprotein and DNA-DNA inter- and intra-strand cross-links (14). It has been reported that cisplatin also induces production of ROS and can bind to mitochondrial DNA (1518). Bleomycin, a conventional antitumor drug for treatment of lymphomas, squamous cell carcinomas and testicular 
tumors, is well-known to cause single- and double-strand breaks in cellular DNA in vivo and in vitro leading finally to genomic instability of damaged cells (19). The mechanism of antineoplastic effect of bleomycin includes formation of bleomycin-iron complex which can reduce molecular oxygen to superoxide and hydroxyl radicals that can attack DNA and cause strand cleavage (1). Many experimental and clinical studies have considered that the antitumor activity of conventional anticancer drugs are usually due to induction of oxidative stress in cancer cells $(1,5,6,8,11)$, but unfortunately side-effects of these anticancer drugs are due to an increased level of ROS in normal cells and disruption of their redox homeostasis $(1-12,20)$. Some of the most effective chemotherapeutics which are used for treatment of variety of cancer types have shown toxic side-effects on noncancer tissues. Efforts are being directed to achieve therapeutic selectivity and to prevent development of drug resistance because it is important to design new strategies that exploit the difference in redox homeostasis between normal cells and cancer cells (21-23).

It is generally accepted that cancer cells are characterized by a higher level of ROS due to mitochondrial dysfunction and up-regulation of the NADPH-dependent oxidase complex (NOX), as well as by a higher level of reducing equivalents due to the abnormal production of $\mathrm{NADP}(\mathrm{H})$ and thiols (e.g. glutathione) as a result of accelerated glycolysis (the Warburg effect) and the pentose-phosphate cycle in comparison with normal cells (21-25). However, these reducers are rapidly consumed in cancer cells, in order to maintain accelerated anabolism, which is necessary for their proliferation and survival $(24,25)$.

A promising strategy for achieving therapeutic selectivity and efficiency in cancer is to take advantage of the fundamental difference between cancer cells and normal cells in their biochemical metabolism. Targeting of unique biochemical alterations in cancer cells might be a feasible approach to achieve therapeutic activity and selectivity and perhaps to prevent the development of drug resistance and undesired side-effects (26-29).

It is assumed that the pentose-phosphate pathway, one of the major branches of the glycolytic pathway, promotes cancer progression, as well as drug resistance, due to the high biosynthetic demands of a rapidly growing cancer cells and their need to adapt to stressful environments $(30,31)$. The pentose-phosphate pathway is essential for the survival of cancer cells because it generates pentose-5-phosphate for the synthesis of nucleotides and reducing equivalent NADPH, which is needed for cell proliferation and regulation of ROS. It has been reported that several oxidative (e.g. glucose-6phosphate dehydrogenase and 6-phospho-gluconate dehydrogenase) and non-oxidative (e.g. transketolase-like-1 and transaldolases) branches of the pentose-phosphate pathway are activated during carcinogenesis (30-34).
An inhibitor of the pentose-phosphate pathway, 6aminonicotine-amide (6-ANA), is in preclinical investigation as a modulator of cytotoxicity of antineoplastic drugs, particularly DNA-damaging chemotherapeutics (35). Data indicate that 6-ANA sensitizes a number of cancer cell lines to doxorubicin, cisplatin, paclitaxel, etc. (36-38). The anticancer activity of 6-ANA is associated with dysregulation of the pentose-phosphate pathway $(39,40)$. 6-ANA is transformed in cells into 6-amino-NADP ${ }^{+}$by $\mathrm{NAD}^{+}$ glycohydrolase. This NADP analog inhibits 6phosphogluconate dehydrogenase much more efficiently than other $\mathrm{NADP}(\mathrm{H})$-requiring enzymes, such as glutathione reductase and glucose-6-phosphate dehydrogenase $(41,42)$.

The aim of the present study was to investigate: (i) the possibility of sensitizing leukemia lymphocytes to anticancer drugs using 6-ANA; (ii) to find combinations with synergistic cytotoxic effect on leukemia lymphocytes and to investigate their cytotoxicity towards normal lymphocytes; (iii) and to clarify the role of ROS in the induction of apoptosis and cytotoxicity by those combinations. The study covers 15 anticancer drugs, both conventional and new-generation.

\section{Materials and Methods}

Cells and treatment protocol. The experiments were performed on Jurkat leukemia lymphocytes derived from patients with acute lymphoblastic leukemia, as well as on normal lymphocytes isolated from healthy blood donors using Lymphosepar-I (ImmunoBiological Laboratories Co., Fujioka, Japan). The cells were cultured in RPMI-1640 medium supplemented with $10 \%$ heatinactivated fetal bovine serum and antibiotics $(100 \mathrm{U} / \mathrm{ml}$ penicillin and $100 \mu \mathrm{g} / \mathrm{ml}$ streptomycin), in a humidified atmosphere at $37^{\circ} \mathrm{C}$ with $5 \% \mathrm{CO}_{2}$. All cells were collected by centrifugation $(1000 \times g$ for $10 \mathrm{~min}$ ) and replaced in fresh medium without antibiotics, before treatment with anticancer drugs.

The drugs were dissolved in dimethyl sulfoxide (DMSO; suitable for cell culture) or phosphate-buffered saline (PBS; $10 \mathrm{mM}, \mathrm{pH}$ 7.4). The final concentration of DMSO in the cell suspension did not exceed $1 \%$. At this concentration, DMSO did not influence cell viability.

The drugs were applied to cells $\left(1 \times 10^{6}\right.$ cells $\left./ \mathrm{ml}\right)$ at the concentrations mentioned below (single dose) and cells were then incubated for different lengths of times intervals in cell incubator. At the end of each time, aliquots were used for cell viability assay.

The cells were incubated with 6-ANA, drug, or drug plus 6-ANA at the following concentrations: $50 \mu \mathrm{M}$ 6-ANA (Sigma-Aldrich, Steinheim, Germany); $0.25 \mu \mathrm{M}$ palbociclib (Selleckchem, Huston, TX, USA); $0.5 \mu \mathrm{M}$ PI-103 (Selleckchem); $5 \mu \mathrm{M}$; everolimus (Selleckchem); 0.5 $\mu \mathrm{M}$ lonafarnib (Selleckchem); $0.1 \mu \mathrm{M}$ ABT-737 (Selleckchem); $0.1 \mu \mathrm{M}$ doxorubicin (Sigma-Aldrich); $0.5 \mu \mathrm{M}$ bleomycin (Nippon Kayaku Co., Tokyo, Japan); $0.1 \mu \mathrm{M}$ AZD-7762 (Sigma-Aldrich); $0.01 \mu \mathrm{M}$ MLN-2238 (Selleckchem); $0.025 \mu \mathrm{M}$ MG-132 (Wako, Tokyo, Japan); $10 \mu \mathrm{M}$ lomustine (Sigma-Aldrich); $2.5 \mu \mathrm{M}$ cisplatin (Selleckchem); 0.025 $\mu \mathrm{M}$ BEZ-235 (Selleckchem); $0.01 \mu \mathrm{M}$ bortezomib (Selleckchem); $0.05 \mu \mathrm{M}$ or $0.01 \mu \mathrm{M}$ barasertib (Selleckchem). The selected concentrations of drugs and 6-ANA (applied separately) induced about $20 \%$ inhibition of cell growth. 
Cell viability assay. Cell viability was analyzed using trypan blue staining and Countess ${ }^{\mathrm{TM}}$ Automated Cell Counter (Invitrogen, OR, USA) at very precise standardization of measurements. Three independent experiments (with two repetitive measurements) for each experiment were performed for each sample. Non-treated cells were used as controls. The data are presented as the mean $\pm \mathrm{SD}$

Intracellular ROS assay. The amount of ROS was analyzed using OxiSelect $^{\mathrm{TM}}$ In Vitro ROS/RNS Assay Kit - Green Flourescence (Cell Biolabs., Inc., San Diego, CA, USA). The method is based on the use of fluorogenic probe, 2',7'-dichlorodihydrofluorescein diacetateDiOxyQ. In the cytosol, the probe is deacetylated to the nonfluorescent form. This in turn reacts with ROS and reactive nitrogen species (RNS) (predominantly $\mathrm{H}_{2} \mathrm{O}_{2}, \mathrm{ROO}^{\circ}, \mathrm{NO}, \mathrm{ONOO}^{-}$) with formation of fluorescent 2',7'-dichlorodihydrofluorescein (DCF). The intensity of DCF fluorescence $\left(\lambda_{\mathrm{ex}}=480 \mathrm{~nm}, \lambda_{\mathrm{em}}=530 \mathrm{~nm}\right)$ is proportional of the amount of ROS/RNS in the biological sample.

The amount of ROS/RNS was calculated by calibration curve based on standard solution of DCF in PBS. The measurements were performed on Tecan Infinite F200 PRO microplate reader (Tecan Austria GmbH, Mannedorf, Austria).

Briefly, the cells $\left(1 \times 10^{6}\right.$ cells $\left./ \mathrm{ml}\right)$ were collected by centrifugation $(1,000 \times g$ for $10 \mathrm{~min})$ and lysed by using $300 \mu \mathrm{l}$ of $0.1 \%$ sodium dodecylsulfate (SDS; dissolved in PBS) within 30 min on ice. The lysates were adjusted to equal protein concentration (range $=1-10 \mathrm{mg} / \mathrm{ml}$ ) using PBS. Protein concentration was analyzed by Bradford assay. Each sample was subjected to ROS/RNS assay, according to the manufacturer's instruction.

Protein-carbonyl assay. The amount of protein-carbonyl products was analyzed using OxiSelect ${ }^{\mathrm{TM}}$ Protein Carbonyl Spectrophotometric Assay Kit (Cell Biolabs, Inc.). The most common products of protein oxidation in biological samples are the protein-carbonyl derivatives of proline, arginine, lysine and threonine. These derivatives are chemically stable and serve as markers of oxidative stress. The analysis of these products is based on derivatization of the carbonyl groups with dinitrophenylhydrazine with formation of proteinhydrazone. The amount of protein-hydrazone is then determined spectrophotometrically at $375 \mathrm{~nm}$.

Briefly, cells $\left(1 \times 10^{6}\right.$ cells $\left./ \mathrm{ml}\right)$ were collected by centrifugation $(1,000 \times g$ for $10 \mathrm{~min})$ and lysed using $300 \mu \mathrm{l}$ of $0.1 \%$ SDS (dissolved in PBS) within $30 \mathrm{~min}$ on ice. The lysates were adjusted to equal protein concentration (range $=1-10 \mathrm{mg} / \mathrm{ml}$ ) using PBS. Protein concentration was analyzed by Bradford assay. Each sample was subjected to protein-carbonyl assay according to the manufacturer's instruction. Oxidized bovine serum albumin was used as a standard.

Apoptosis assay. The induction of apoptosis was analyzed by the expression of phosphatidylserine (PSer) on the cell surface using FITC-Annexin V Apoptosis Detection Kit (BioVision, Milpitas, CA, USA).

Briefly, cells $\left(1 \times 10^{6}\right.$ cells $\left./ \mathrm{ml}\right)$ were incubated with drug, 6-ANA or their combination, under the conditions mentioned above. At each time-point, the cells were collected by centrifugation $(1,000 \times g$ for $10 \mathrm{~min}$ ), washed twice with PBS containing $2.5 \mathrm{mM} \mathrm{CaCl}_{2}$ (annexin V-binding buffer) and re-suspended in the same buffer. One hundred microliters of the suspension were incubated with $5 \mu \mathrm{l}$ of fluorescein isothiocyanate (FITC)-annexin V for $10 \mathrm{~min}$ at room temperature in the dark. The cells were then washed three times with annexin V-binding buffer and finally were re-suspended in $500 \mu \mathrm{l}$ of the same buffer. FITC-annexin V bound to PSer exposed on the cell surface was detected spectrofluorimetrically at $\lambda_{\mathrm{ex}}=488$ $\mathrm{nm}$ and $\lambda_{\mathrm{em}}=535 \mathrm{~nm}$ using Tecan Infinite F200 PRO microplate reader (Tecan Austria GmbH).

Statistical analysis. The results are expressed as the mean \pm SD. Statistical analysis was performed with Student's $t$-test. A value of $p<0.05$ was considered significant.

\section{Results and Discussion}

The data in Figure 1 demonstrate the viability of leukemia lymphocytes (Jurkat) and normal lymphocytes after treatment by 6-ANA at different concentrations and for different times. Applied alone in concentrations in the range of 5 to $50 \mu \mathrm{M}$, 6-ANA exhibited cytotoxicity only towards leukemia lymphocytes not to normal lymphocytes. At a concentration of $50 \mu \mathrm{M}, 6$-ANA caused about $20 \%$ inhibition of cell proliferation $\left(\mathrm{IC}_{20}\right)$ in leukemia lymphocytes (Figure 1A) without cytotoxic effect on normal lymphocytes after 48-h incubation (Figure 1B). This concentration was selected for further experiments.

Several groups have also described a relatively high anticancer activity of 6-ANA (over $25 \mu \mathrm{M}$ ) against cultured cell lines (36-45) and low cytotoxicity towards noncancerous cells (45). In these studies, the inhibition of pentose-phosphate pathway was recognized as a major mechanism for induction of apoptosis in cancer cells (36-45). Other studies demonstrated that 6-ANA inhibits poly(ADPribose) polymerase (PARP), with the result that PARP cannot participate in DNA repair after induction of oxidative damage (46-48). However, it is still unclear whether the inhibition of PARP by 6-ANA is responsible for induction of apoptosis in cancer cells.

In the second part of our study, Jurkat cells were treated with: (i) drug only; (ii) 6-ANA only; and (iii) combination of drug and 6-ANA. The aim of this step of the study was to find combinations with synergistic cytotoxic effects on leukemia cells. Figure 2 shows the proliferation of Jurkat cells treated with 6-ANA in the absence and presence of drug for 24-72 hours. In order to distinguish synergistic effects from antagonistic/additive effects in combinations, we calculated the effect of each combination on cell proliferation as a percentage of the effect of the respective drug applied alone and compared it with the effect of 6-ANA applied alone, as described previously (29). The red line in Figure 2B indicates the effect of 6-ANA alone on cancer cell proliferation. In the case of drug plus 6-ANA, data located to the left of the red line reflect synergistic cytotoxic effects, while the data located to the right of the red line represent antagonistic effects. All data matching the red line reflect an additive affect. The cytotoxicity of each drug (applied separately at the selected concentration) ranged from about 

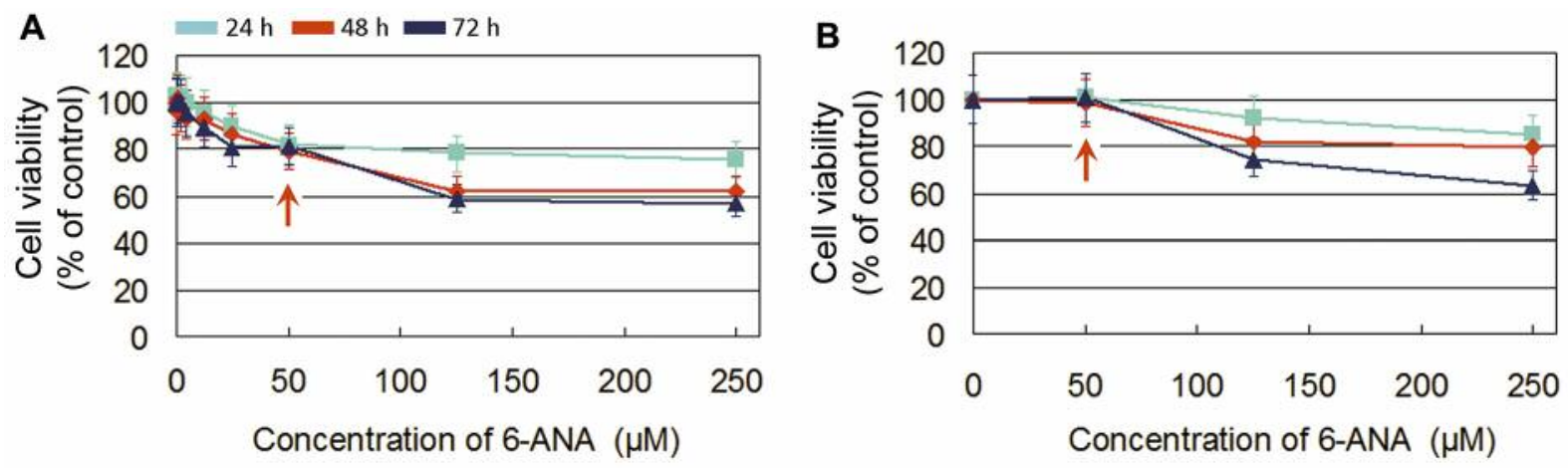

Figure 1. Effect of 6-amino-nicotinamide (6-ANA) on viability of leukemia lymphocytes Jurkat (A) and normal lymphocytes (B) at different incubation times - concentration dependent curves. The data are the mean $\pm S D$ from six independent experiments. The red arrow indicates the concentration of 6-ANA $(50 \mu \mathrm{M})$, selected for further experiments in combination with anticancer drugs.

$10-20 \%$ after $24-\mathrm{h}$ incubation to about $20-30 \%$ after 48 -h and 72-h incubation.

Most of the combinations (drug plus 6-ANA) were characterized by synergistic cytotoxic effects on Jurkat cells compared with cells treated with drug only (Figure 2B). The synergism increased with incubation time. The greatest synergistic cytotoxic effects were observed after treatment of Jurkat cells with 6-ANA in combination with bortezomib, barasertib, everolimus, lonafarnib, or palbociclib.

Two of these synergistic combinations were selected for the next step of this study, namely everolimus plus 6-ANA and barasertib plus 6-ANA. In our recent study, we observed that everolimus and barasertib (applied alone) did not increase the level of ROS in leukemia and normal lymphocytes (49). In addition, we selected a combination of 6-ANA with the conventional anticancer drug doxorubicin, which is known to increase ROS in cancer and normal cells (11-13). We investigated the effect of these combinations on viability of normal lymphocytes and clarified whether their synergistic cytotoxicity was accompanied by enhancement of ROS and induction of apoptosis in both cell types (leukemia and normal).

Doxorubicin, at a concentration of $0.1 \mu \mathrm{M}$, was equally cytotoxic towards leukemia and normal lymphocytes (Figure 3 ). Cytotoxicity increased with incubation time, from $\sim 5-10 \%$ after $24 \mathrm{~h}$ up to $\sim 25 \%$ after $48 \mathrm{~h}$. This was accompanied by increased levels of ROS and protein-carbonyl products and induction of apoptosis, especially at $48 \mathrm{~h}$. 6-ANA increased the cytotoxicity of doxorubicin by up to $40 \%$ for both cell types, which was accompanied by increased induction of apoptosis via ROS-independent mechanism(s): the levels of ROS and protein-carbonyl products were actually slightly or significantly lower than in cells treated with doxorubicin only. The synergistic cytotoxicity of doxorubicin plus 6-ANA might be attributed to effect of both compounds on several onco-targets, but not to overproduction of ROS. It was reported that 6-ANA increases the sensitivity of doxorubicinresistant cell lines to tumor necrosis factor alpha via downregulation of human epidermal growth factor receptor (50). 6-ANA regulates the level of glutathione and inhibits multidrug resistance-associated proteins in doxorubicinresistant and doxorubicin-sensitive cell lines (38).

Everolimus is an inhibitor of the mammalian target of rapamycin (mTOR) pathway, which plays a fundamental role in the regulation of cell viability, translational initiation, and cell-cycle progression. This drug is usually used in the clinic as an immunosuppressant to prevent rejection of organ transplants. In the past 10 years, it was found that everolimus also possesses anticancer activity (51-59). It sensitizes cancer cells to other anticancer drugs, as well as preventing the development of multidrug resistance through altering the balance between pro-apoptotic and anti-apoptotic factors (56, 59). Schwarz et al. showed that the anticancer effect of everolimus was not mediated by increased production of ROS (60), but Pignochino et al. suggested the involvement of ROS in this process (61).

Our study shows that everolimus, at $5 \mu \mathrm{M}$, exhibited cytotoxicity ( $\sim 10-15 \%$ after 48 -h incubation) towards Jurkat cells but not towards normal lymphocytes (Figure 4). In Jurkat cells, the cytotoxicity of everolimus applied alone was accompanied by strong induction of apoptosis but a relatively slight (insignificant) increase of the level of ROS and without changes in the level of protein-carbonyl products. 6-ANA increased the cytotoxicity of everolimus towards leukemia lymphocytes by up to $\sim 60 \%$ after 48 -h incubation, but the combination did not affect the viability of normal lymphocytes. In Jurkat cells, 6-ANA significantly increased (up to 2.5 times) the induction of apoptosis by everolimus, but reduced the level of ROS below that even of the control (Figure 4A). In normal lymphocytes, the combination did not affect the level of ROS nor the level of protein-carbonyl products and apoptosis (Figure 4B). 

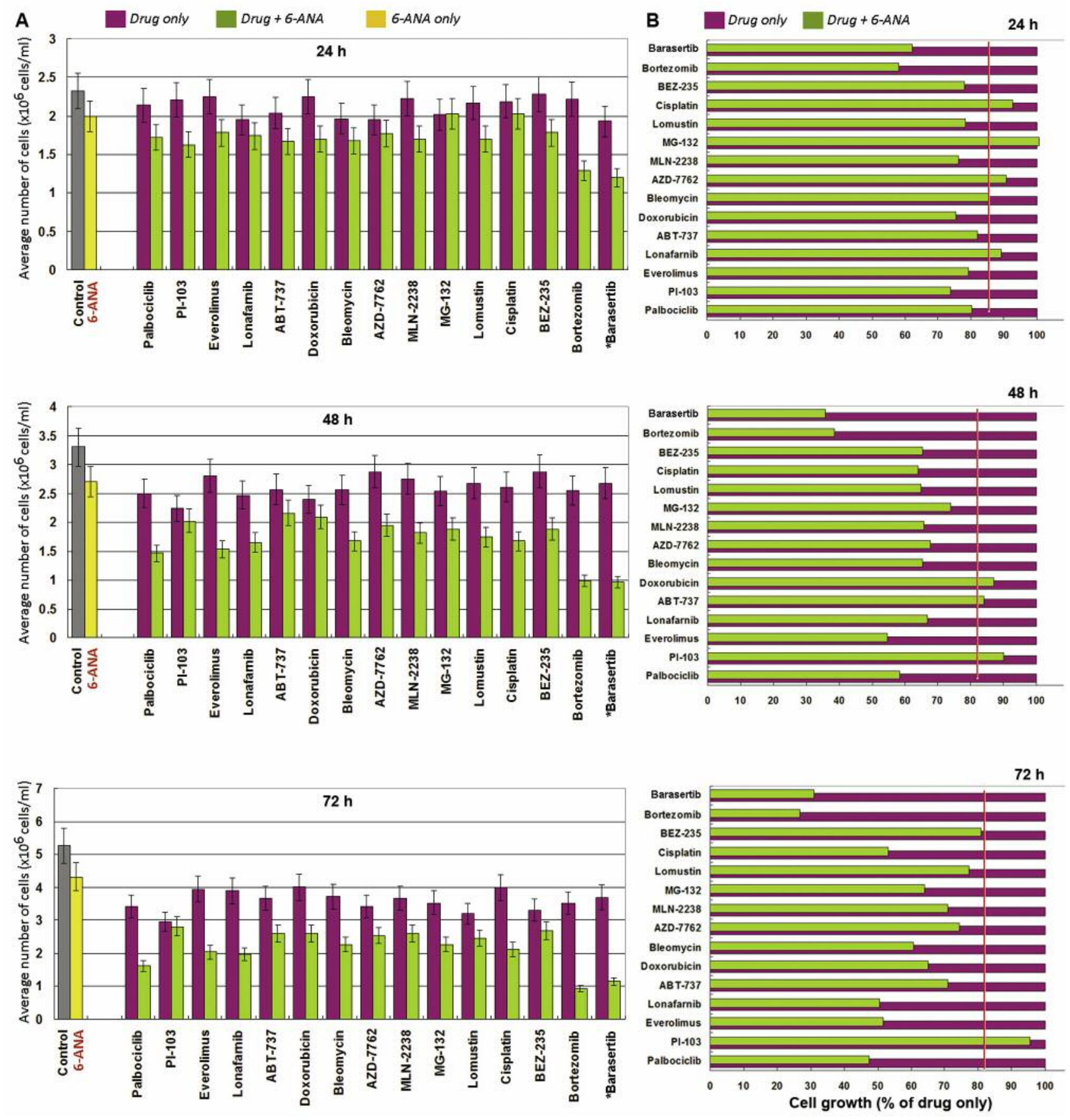

Figure 2. A: Effect of 6-amino-nicotinamide (6-ANA; $50 \mu \mathrm{M})$ and anticancer drugs (at concentrations given in the Materials and Methods) on proliferation of Jurkat cells after incubation for 24, 48 and $72 \mathrm{~h}$. The data are the mean $\pm S D$ from six independent experiments. B: Effect of each combination (drug plus 6-ANA) on cell proliferation as a percentage of the effect of that when the drug was applied alone. The red line indicates the effect of 6-ANA on cell proliferation of cancer cells as a percentage of the control (untreated cells). *In this experiment, the concentration of barasertib was $50 \mathrm{nM}$.

Similar tendencies were observed in cells treated with barasertib and its combination with 6-ANA (Figure 5). Both cell lines were treated with a very low concentration of barasertib $(10 \mathrm{nM})$. At this concentration, barasertib applied alone did not affect the viability of either cell type. However, its combination with 6-ANA induced a very strong cytotoxic effect on Jurkat cells ( 75\%), which was accompanied by strong induction of apoptosis and relatively moderate 
A

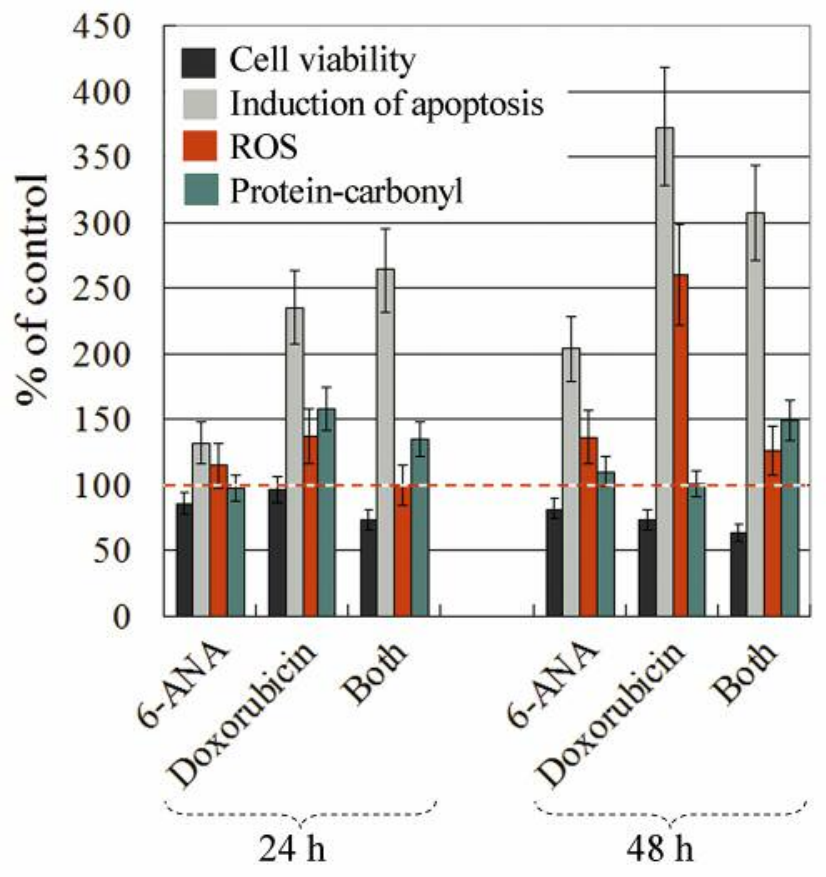

B

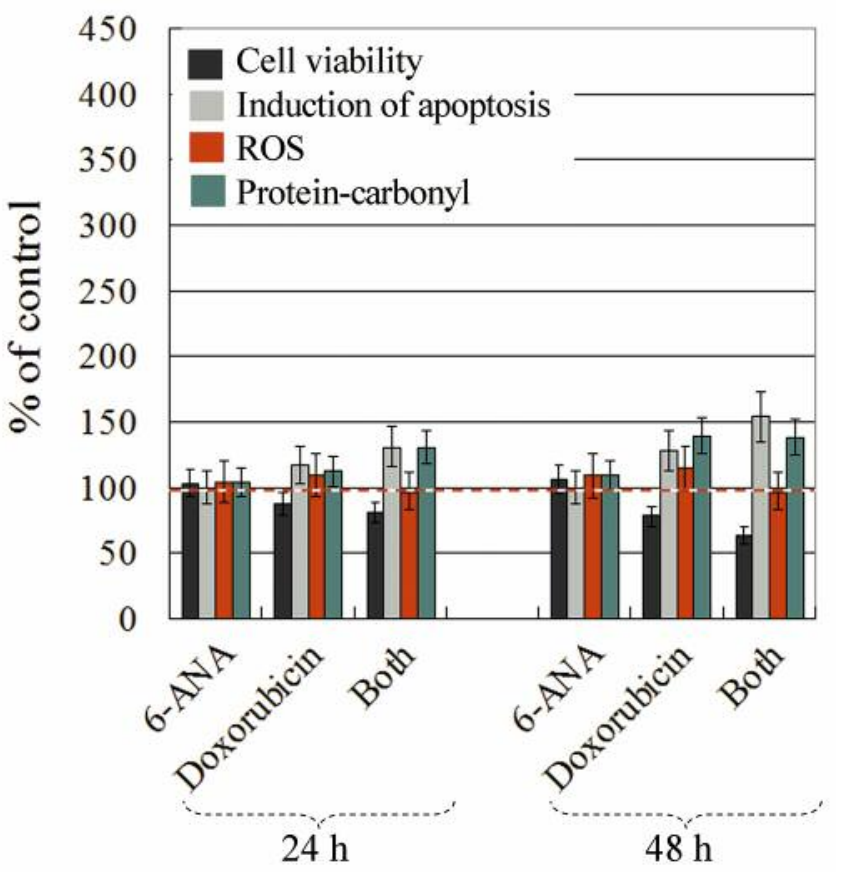

Figure 3. Effects of 6-amino-nicotinamide (6-ANA; $50 \mu \mathrm{M})$, doxorubicin $(0.1 \mu \mathrm{M})$ and their combination on cell viability, induction of apoptosis, reactive oxygen species (ROS) and protein-carbonyl products in Jurkat leukemia cells (A) and normal lymphocytes (B) after 24-and 48-h incubation at $37^{\circ} \mathrm{C}$ in a humidified atmosphere. The data are the mean $\pm S D$ from three independent experiments.

A

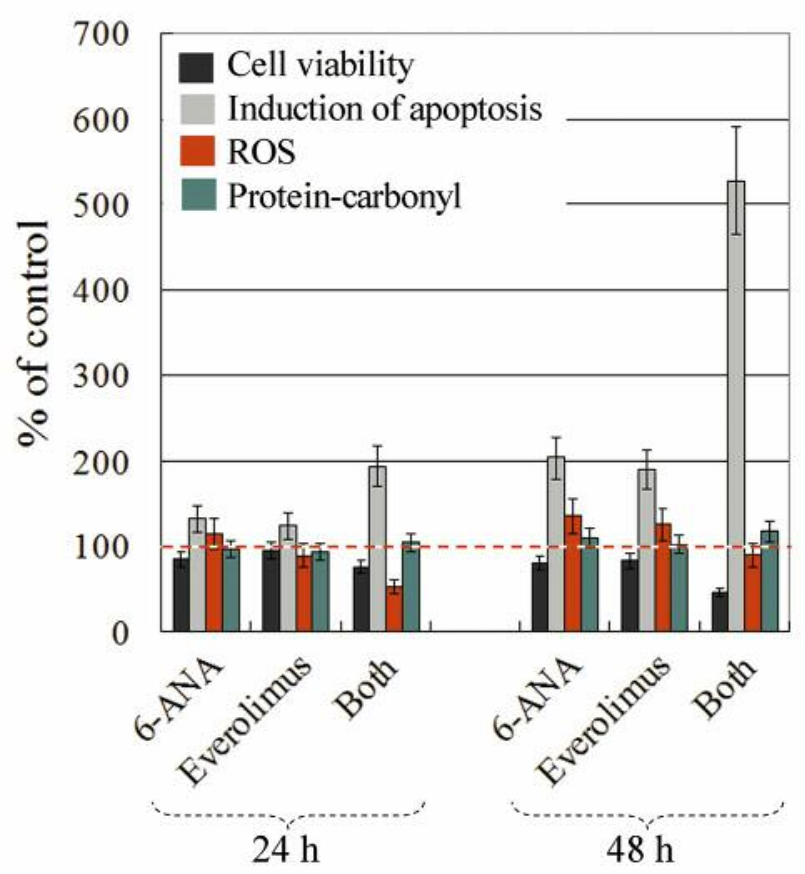

B

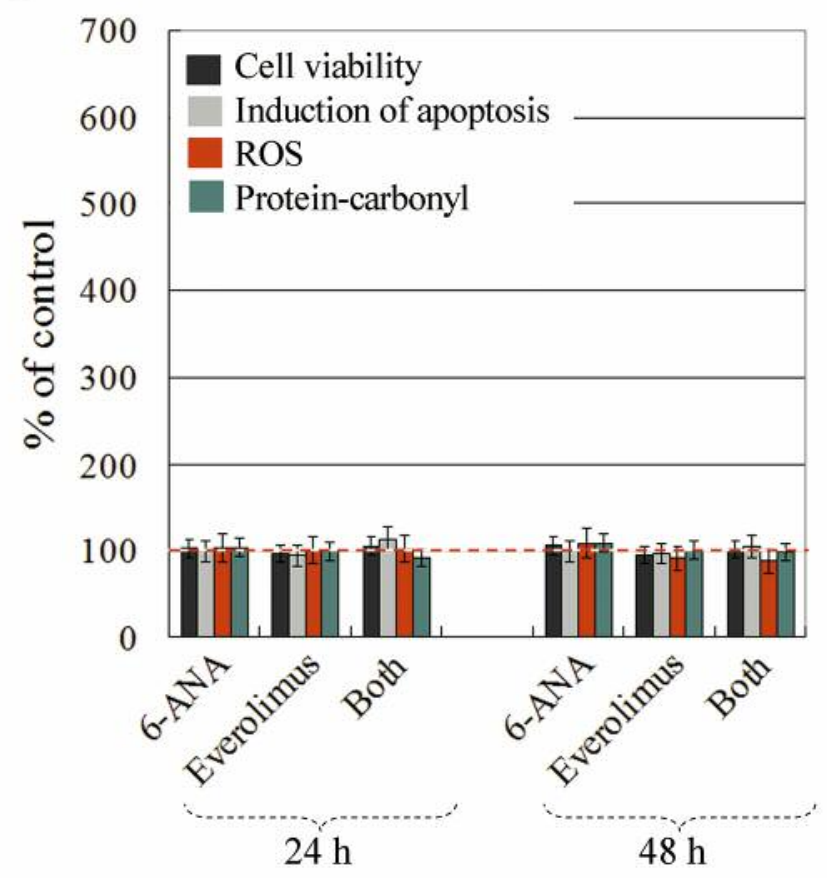

Figure 4. Effects of 6-amino-nicotinamide (6-ANA; $50 \mu \mathrm{M})$, everolimus $(5 \mu \mathrm{M})$ and their combination on cell viability, induction of apoptosis, reactive oxygen species (ROS) and protein-carbonyl products in Jurkat leukemia cells (A) and normal lymphocytes (B) after 24-and 48-h incubation at $37^{\circ} \mathrm{C}$ in a humidified atmosphere. The data are the mean $\pm S D$ from three independent experiments. 
A

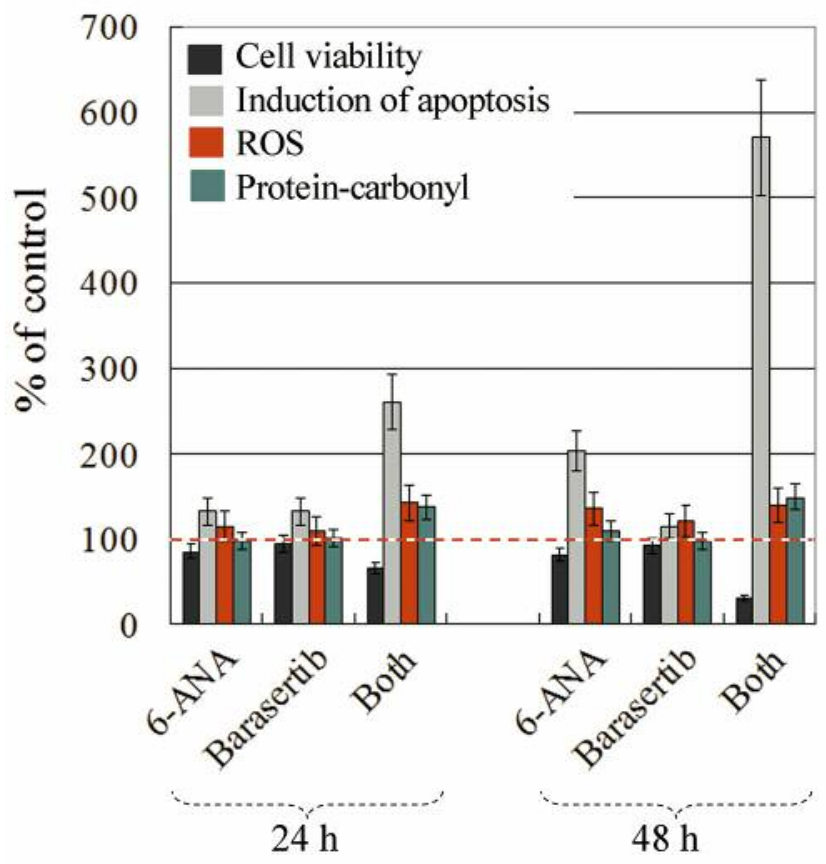

B

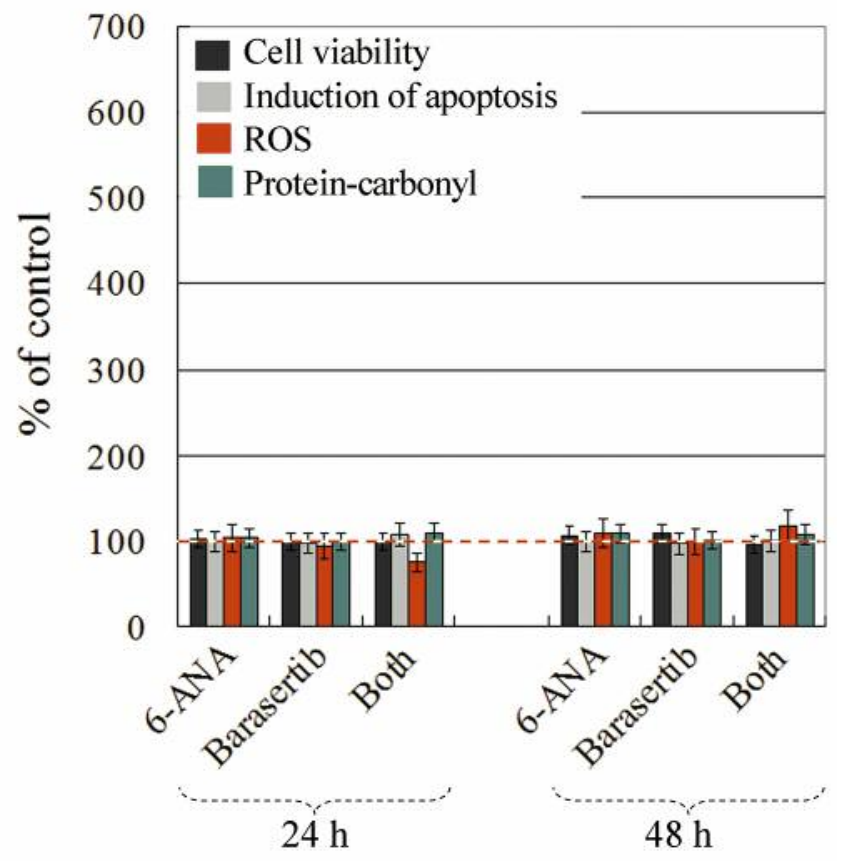

Figure 5. Effects of 6-amino-nicotinamide (6-ANA; $50 \mu M)$, barasertib $(0.01 \mu M)$ and their combination on cell viability, induction of apoptosis, reactive oxygen species (ROS) and protein-carbonyl products in Jurkat leukemia cells (A) and normal lymphocytes (B) after 24-and 48-h incubation at $37^{\circ} \mathrm{C}$ in a humidified atmosphere. The data are the mean \pm SD from three independent experiments .

enhancement of ROS and protein-carbonyl levels, as detected after 48-h incubation (Figure 5A). In normal lymphocytes, the combination did not affect the level of ROS and proteincarbonyl products, nor did it induce apoptosis (Figure 5B).

Barasertib belongs to a new class of pyrazoloquinazolines, selective inhibitors of aurora B kinase, discovered and described in 2007 (62). The aurora kinases have been the subject of considerable interest as targets for the development of new anticancer agents. Little is known about the molecular mechanisms of action of barasertib, except that it inhibits aurora B kinase, and provokes cell-cycle arrest and apoptosis, as well as enhancing the response to chemotherapy (63-65).

In the literature, there are many data regarding sensitizing cancer cells to conventional anticancer drugs (such as doxorubicin, bleomycin, and cisplatin) by inhibitors of the pentose-phosphate cycle $(31,32,66,67)$. Most of them suggest ROS-dependent mechanisms. A limited number of studies describe the effect of 6-ANA on the cytotoxicity of new-generation anticancer drugs (recently approved for clinical use or still in clinical trials), such as the proteasome inhibitor MG-132 (68). As far as we are aware, there are no data about the effect of 6-ANA on the efficiency of newgeneration anticancer drugs such as AZD7762 (selective inhibitor of checkpoint kinases), ABT-737 (selective inhibitor of B-cell lymphoma 2 proteins), barasertib (selective inhibitor of aurora B kinase), everolimus (mTOR inhibitor), lonafarnib (farnesyltrasferase inhibitor), MLN-2238 and bortezomib (proteasome inhibitors), and palbociclib (selective inhibitor of cyclin-dependent kinases). To our knowledge, our study is the first to report synergistic cytotoxicity between 6-ANA (as a redox modulator) and both everolimus and barasertib (as anticancer drugs) which is ROS-independent and specific for cancer cells (particularly for Jurkat acute lymphoblastic leukemia cells). These combinations are harmless to normal lymphocytes and do not induce production of ROS in those cells. The data suggest that 6-ANA could be used as a supplementary component in anticancer chemotherapy, which would allow reduction of the therapeutic doses of barasertib and everolimus, minimizing their side-effects. This statement can also be made for all the anticancer drugs investigated here, whose cytotoxicity increased by combining them with 6-ANA.

\section{Acknowledgements}

The study was partially supported by the Center of Innovation Program from the Japan Science and Technology Agency and by the Diversity Grant, NIRS-Chiba University, Japan (granted to R.A.). 


\section{References}

1 Hagiwara SI, Ishii Y and Kitamura S: Aerosolized administration of $\mathrm{N}$-acetylcysteine attenuates lung fibrosis induced by bleomycin in mice. Am J Respir Crit Care Med 162: 225-231, 2000.

2 Satoh M, Kashihara N, Fujimoto S, Horike H, Tokura T, Namikoshi T, Sasaki $\mathrm{T}$ and Makino $\mathrm{H}$ : A novel free radical scavenger, edarabone, protects against cisplatin-induced acute rental damage in vitro and in vivo. J Pharmacol Exp Ther 305: 1183-1190, 2003.

3 Tsang WP, Chau SPY, Kong SK, Fung KP and Kwok TT: Reactive oxygen species mediated doxorubicin induced p-53independent apoptosis. Life Sci 73: 2047-2058, 2003.

4 Hartog GJ, Haenen GR, Boven E, van der Vijgh WJ and Bast A: Lecithinized copper, zinc-superoxide dismutase as a protector against doxorubicin-induced cardiotoxicity in mice. Toxicol Appl Pharmacol 194: 180-188, 2004.

5 Mizutan H, Oikawa ST, Hirak J, Kojiama M and Kawanishi S: Mechanism of apoptosis by doxorubicin throught the generation of hydrogen peroxide. Life Sci 76: 1439-1453, 2005

6 Salvatorelli E, Guarnieri S, Menna P, Liberi G, Calafiore AM, Mariggio MA, Mordente A, Gianni L and Minotti G: Defective one- or two-electron reduction of the anticancer anthracycline Epirubicin in human heart. J Biol Chem 281: 10990-11001, 2006.

7 Tsai SY, Sung NK, Lu HP, Cheng ML and Chao CCK: Involment of reactive oxygen species in multidrug resistance of vincristineselected lymphoblastoma. Cancer Sci 98: 1206-1214, 2007.

8 Wang J and Yi J: Cancer cell killing via ROS. Cancer Biol Ther 7: 1875-1884, 2008.

9 Dickey JS and Rao VA: Current and proposed biomarkers of anthracycline cardiotoxicity in cancer: emerging opportunities in oxidative damage and autophagy. Curr Mol Med 12: 763-771, 2012.

10 Angsutararus P, Luanpitpong S and Issaragrisil S: Chemotherapyinduced cardiotoxicity: review of the roles of oxidative stress. Oxid Med Cell Longev 2015: 795602, 2015.

11 Ozben T: Oxidative stress and apoptosis: impact on cancer therapy. J Pharm Sci 96: 2181-2196, 2007.

12 Danz EDB, Skramsted J, Henry N, Bennett JA and Keller RS: Resveratrol prevents doxorubicin cardiotoxicity through mitochondrial stabilization and SIRT1 pathway. Free Radic Biol Med 46: 1589-1597, 2009.

13 Kuznetsov AV, Margreiter R, Amberger A, Saks V and Grimm $\mathrm{M}$ : Changes in mitochondrial redox state, membrane potential and calcium precede mitochondrial dysfunction in doxorubicininduced cell death. Biochim Biophys Acta 1813: 1144-1152, 2011.

14 Trajkovic LH, Vilimanovich U, Stevovic TK, Bumbasirevic V and Trajkovic V: AMPK-mediated autophagy inhibits apoptosis in cisplatin-treated tumor cells. J Cell Mol Med 13: 3644-3654, 2009.

15 Mandic A, Hansson J, Linder S and Shoshan MC: Cisplatin induced endoplasmic reticulum stress and nucleus-independent apoptotic signaling. J Biol Chem 278: 9100-9106, 2003.

16 Deavall DG, Martin EA, Horner JM and Roberts R: Drug-induced oxidative stress and toxicity. J Toxicol 2012: 645460, 2012.

17 Pariente R, Pariente JA, Rodriguez AB and Espino J: Melatonin sensitizes human cervical cancer HeLa cells to cisplatin-induced cytotoxicity and apoptosis: effects on oxidative stress and DNA fragmentation. J Pineal Res 60: 55-64, 2016.
18 Pluchino LA, Choudhary S and Wang HR: Reactive oxygen species-mediated synergistic and preferential induction of cell death and reduction of clonogenic resistance in breast cancer cells by combined cisplatin and FK228. Cancer Lett 381: 124132, 2016.

19 Kasper M and Barth K: Bleomycin and its role in inducting apoptosis and senescence in lung cells - modulating effects of caveolin-1. Curr Cancer Drug Targets 9: 341-353, 2009.

20 De Larco JE, Park CA, Dronava H and Furcht LT: Paradoxical roles for antioxidants in tumor prevention and eradication. Cancer Biol Ther 9: 362-370, 2010.

21 Trachootham D, Alexandre J and Huang P: Targeting cancer cells by ROS-mediated mechanisms: a radical therapeutic approach? Nat Rev Drug Discovery 8: 579-591, 2009.

22 Chen G, Izzo J, Demizu Y, Wang F, Guha S, Wu X, Hung MC, Ajani JA and Huang P: Different redox states in malignant and nonmalignant esophageal epithelial cells and differential cytotoxic responses to bile acid and honokiol. Antioxid Redox Signal 11: 1083-1095, 2009.

23 Ivanova D, Bakalova R, Lazarova D, Gadjeva V and Zhelev Z: The impact of reactive oxygen species on anticancer therapeutic strategies. Adv Clin Exp Med 22: 899-908, 2013.

24 Zhelev Z, Aoki I, Gadjeva V, Nikolova B, Bakalova R and Saga $\mathrm{T}$ : Tissue redox activity as a sensing platform for imaging of cancer based on nitroxide redox cycle. Eur J Cancer 49: 14671478, 2013.

25 Bakalova R, Zhelev Z, Aoki I and Saga T: Tissue redox activity as a hallmark of carcinogenesis: from early to terminal stages of cancer. Clin Cancer Res 19: 2503-2517, 2013.

26 Chen G, Wang F, Trachootham D and Huang P: Preferantial killing of cancer cells with mitochondrial dysfunction by natural compounds. Mitochondrion 10: 614-625, 2010.

27 Herbel C, Patsoukis N, Bardhan K, Seth, Weaver JD and Boussiotis VA: Clinical significance of T-cell metabolic reprogramming in cancer. Curr Transl Med 6: 29, 2016.

28 Cruys B, Wong BW, Kuchnio A, Verdegem D, Cantelmo AR, Conradi LC, Vandekeere S, Bouché A, Cornelissen I, Vinckier S, Merks RM, Dejana E, Gerhardt H, Dewerchin M, Bentley K and Carmeliet P: Glycolytic regulation of cell rearrangement in angiogenesis. Nat Commun 7: 12240, 2016.

29 Zhelev Z, Ivanova D, Aoki I, Saga T and Bakalova R: 2-DeoxyD-glucose sensitizes cancer cells to barasertib and everolimus by ROS-independent mechanism(s). Anticancer Res 35: 66236632, 2015.

30 Tsouko E, Khan AS, White MA, Han JJ, Shi Y, Merchant FA, Sharpe MA, Xin L and Frigo ED: Regulation of the pentose phosphate pathway by an androgen receptor-mTOR-mediated mechanism and its role in prostate cancer cell growth. Oncogenesis 3: 1-10, 2014.

31 Riganti C, Gazzano E, Polimeni M, Aldieri E and Ghigo D: The pentose phosphate pathway: an antioxidant defense and a crossroad in tumor cell fate. Free Radic Biol Med 5: 421-436, 2012.

$32 \mathrm{Lu} \mathrm{W,} \mathrm{Logsdon} \mathrm{CD} \mathrm{and} \mathrm{Abbruzzes} \mathrm{JL:} \mathrm{Cancer} \mathrm{metabolism} \mathrm{and}$ its therapeutic implication. J Cell Sci Ther 4: 1-10, 2013.

33 Coy JF, Dressler D, Wilde J and Schubert P: Mutations in the transketolaselike gene TKTL1: clinical implications for neurodegenerative diseases, diabetes and cancer. Clin Lab 51: 257-273, 2005.

34 Langbein S, Zerilli M, Zur Hausen A, Staiger W, RenschBoschert K, Lukan N, Popa J, Ternullo MP, Steidler A, Weiss C, 
Grobholz R, Willeke F, Alken P, Stassi G, Schubert P and Coy JF: Expression of transketolase TKTL1 predicts colon and urothelial cancer patient survival: Warburg effect reinterpreted. Br J Cancer 94: 578-585, 2006.

35 Walker DL, Reid JM, Svingen PA, Rios R, Covey JM, Alley MC, Hollingshead MG, Budihardjo II, Eckdahl S, Boerner SA, Kaufmann SH and Ames MM: Murine pharmacokinetics of 6amininicotinamide (NSC21206), a novel biochemical modulating agent. Biochem Pharmacol 58: 1057-1066, 1999.

36 Martin DS, Stolfi RL, Colofiore JR and Nord LD: Marked enhancement in vivo of paclitaxel's (taxol's) tumor-regressing activity by ATP-depleting modulation. Anticancer Res 7: 655$659,1996$.

37 Budihardjo II, Boerner SA, Eckdahl S, Svingen PA, Rios R, Ames MM and Kaufmann SH: Effect of 6-aminonicotinamide and other protein synthesis inhibitors on formation of platinumDNA adducts and cisplatin sensitivity. Mol Pharmacol 57: 529538, 2000.

38 Polimeni M, Voena C, Kopecka J, Riganti C, Pescarmona G, Bosia A and Ghigo D: Modulation of doxorubicin resistance by the glucose-6-phosphate dehydrogenase activity. Biochem J 439: 141-149, 2011.

39 Cairns RA., Harris IS and Mak TW: Regulation of cancer cell metabolism. Nat Rev Cancer 11: 85-95, 2011.

40 Jiang P, Du W and Wu M: Regulation of the pentose phosphate pathway in cancer. Protein Cell 5: 592-602, 2014.

41 Hothersall JS, Gordge M and Noronha-Dutra AA: Inhibition of NADPH supply by 6-aminonicotinamide: effect on glutathione, nitric oxide and superoxide in J774 cells. FEBS Lett 434: 97100,1998

42 Sharma PK and Varshney R: 2-Deoxy-D-glucose and 6aminonicotinamide-mediated Nrf2 down-regulation leads to radiosensitization of malignant cells via abrogation of GSHmediated defense. Free Radic Res 46: 1446-1457, 2012.

43 Chatterjee S, Hirota H, Belfi CA, Sosamma BJ and Berger NA: Hypersensitivity to DNA cross-linking agents associated with up-regulation of glucose-regulated stress protein GRP78. Cancer Res 57: 5112-5116, 1997.

44 Debeb BG, Lacerda L, Larson R, Wolfe AR, Krishnamurthy S, Reuben JM, Ueno NT, Gilcrease M and Woodward WA: Histone deacetylase inhibitor-induced cancer stem cells exhibit high pentose phosphate pathway metabolism. Oncotarget 7: 2832928339, 2016.

45 Pelicano H, Martin DS, Xu R-H and Huang H. Glycolysis inhibition for anticancer therapy. Oncogene 25: 4633-4646, 2006.

46 Ogata S, Takeuchi M, Fujita H, Shibata K, Okumura K and Taguchi H: Apoptosis induced by nicotinamide-related compounds and quinolinic acid in HL-60 cells. Biosci Biotachnol Biochem 64: 327-332, 2000.

47 Budihardjo II, Walker DL, Svingen PA, Buckwalter CA, Desnoyers S, Eckdahl S, Shah GM, Poirier GG, Reid JM, Ames MM and Kaufmann SH: 6-Aminonicotinamide sensitizes human tumor cell lines to cisplatin. Clin Cancer Res 4: 117-130, 1998

48 Sims JL, Sikorski GW, Catino DM, Berger SJ and Berger NA: Poly(adenosinediphosphoribose) polymerase inhibitors stimulate unscheduled deoxyribonucleic acid synthesis in normal human lymphocytes. Biochemistry 21: 1813-1821, 1982.

49 Zhelev Z, Ivanova D, Lazarova D, Aoki I, Bakalova R and Saga T: 2-Docosahexaenoic acid sensitizes leukemia lymphocytes to barasertib and everolimus by ROS-dependent mechanism without affecting the level of ROS and viability of normal lymphocytes. Anticancer Res 36: 1673-1682, 2016.

50 Sleijfer S, Asschert JG, Timmer-Bosscha $\mathrm{H}$ and Mulder NH: Enhanced sensitivity to tumor necrosis factor-alpha in doxorubicin-resistant tumor cell lines due to down-regulated cerbB2. Int J Cancer 77: 101-106, 1998.

51 Majumder PK, Febbo PG, Bikoff R, Berger R, Xue Q, McMahon LM, Manola J, Brugarolas J, McDonnell TJ, Golub TR, Loda M, Lane HA and Sellers WR: mTOR inhibition reverses AKT-dependent prostate intraepithelial neoplasia through regulation of apoptotic and HIF-1-dependent pathways. Nat Med 10: 594-601, 2004.

52 Witzig TE, Reeder C, Han JJ, LaPlant B, Stenson M, Tun HW, Macon W, Ansell SM, Habermann TM, Inwards DJ, Micallef IN, Johnston PB, Porrata LF, Colgan JP, Markovic S, Nowakowski GS and Gupta M: The mTORC1 inhibitor everolimus has antitumor activity in vitro and produces tumor responses in patients with relapsed T-cell lymphoma. Blood 126: 328-335, 2015.

53 Daver N, Boumber Y, Kantarjian H, Ravandi F, Cortes J, Rytting ME, Kawedia JD, Basnett J, Culotta KS, Zeng Z, Lu H, Richie MA, Garris R, Xiao L, Liu W, Baggerly KA, Jabbour E, O'Brien S, Burger J, Bendall LJ, Thomas D and Konopleva M: A phase I/II study of the mTOR inhibitor everolimus in combination with hyperCVAD chemotherapy in patients with relapsed/refractory acute lymphoblastic leukemia. Clin Cancer Res 21: 2704-2714, 2015.

54 Baraz R, Cisterne A, Saunders PO, Hewson J, Thien M, Weiss $\mathrm{J}$, Basnett J, Bradstock KF and Bendall LJ: mTOR inhibition by everolimus in childhood acute lymphoblastic leukemia induces caspase-independent cell death. PLoS One 9: e102494, 2014.

55 Serra V, Markman B, Scaltriti M, Eichhorn PJ, Valero V, Guzman M, Botero ML, Llonch E, Atzori F, Di Cosimo S, Maira M, Garcia-Echeverria C, Parra JL, Arribas J and Baselga J: NVP-BEZ235, a dual PI3K/mTOR inhibitor, prevents PI3K signaling and inhibits the growth of cancer cells with activating PI3K mutations. Cancer Res 68: 8022-8030, 2008.

56 Dengler J, von Bubnoff N, Decker T, Peschel C and Duyster J: Combination of imatinib with rapamycin or RAD001 acts synergistically only in BCR-ABL-positive cells with moderate resistance to imatinib. Leukemia 19: 1835-1838, 2015.

57 Mancini M, Corradi V, Petta S, Martinelli G, Barbieri E and Santucci MA: mTOR inhibitor RAD001 (Everolimus) enhances the effects of imatinib in chronic myeloid leukemia by raising the nuclear expression of c-ABL protein. Leuk Res 34: 641-648, 2010.

58 Calabro A, Tai J, Allen SL and Budman DR: In vitro synergism of m-TOR inhibitors, statins, and classical chemotherapy: potential implications in acute leukemia. Anticancer Drugs 19: 705-712, 2008

59 Harituninians T, Mori A, O’Kelly J, Luong QT, Giles FJ and Koeffler HP: Antiproliferative activity of RAD001 (everolimus) as a single agent and combined with other agents in mantle cell lymphoma. Leukemia 21: 333-339, 2007.

60 Schwarz JBK, Langwieser N, Langwieser NN, Bek MJ, Seidl S, Eckstein H-H., Lu B, Schomig A, Pavenstadt $\mathrm{H}$ and Zohlnhofer D: Novel role of the CXC chemokine receptor 3 in inflammatory response to arterial injury: involvement of mTORC1. Circ Res 104: 189-200, 2009. 
61 Pignochino Y, Dell'Aglio C, Basiricò M, Capozzi F, Soster M, Marchiò S, Bruno S, Gammaitoni L, Sangiolo D, Torchiaro E, D’Ambrosio L, Fagioli F, Ferrari S, Alberghini M, Picci P, Aglietta $\mathrm{M}$ and Grignani G: The combination of sorafenib and everolimus abrogates $m$ TORC1 and $m$ TORC 2 up-regulation in osteosarcoma preclinical models. Clin Cancer Res 19: 2117$2131,2013$.

62 Mortlock AA, Foote KM, Heron NM, Jung FH, Pasquet G, Lohmann JJ, Warin N, Renaud F, De Savi C, Roberts NJ, Johnson T, Dousson CB, Hill GB, Perkins D, Hatter G, Wilkinson RW, Wedge SR, Heaton SP, Odedra R, Keen NJ, Crafter C, Brown E, Thompson K, Brightwell S, Khatri L, Brady MC, Kearney S, McKillop D, Rhead S, Parry T and Green S: Discovery, synthesis, and in vivo activity of a new class of pyrazoloquinazolines as selective inhibitors of aurora B kinase. J Med Chem 50: 2213-2224, 2007.

63 Porcelli L, Guida G, Quatrale AE, Cocco T, Sidella L, Maida I, Iacobazzi RM, Ferretta A, Stolfa DA, Strippoli S, Guida S, Tommasi S, Guida M and Azzariti A: Aurora kinase B inhibition reduces the proliferation of metastatic melanoma cells and enhances the response to chemotherapy. J Transl Med 13: 26, 2015.

64 Boeckx C, Op de Beeck K, Wouters A, Deschoolmeester V, Limame R, Zwaenepoel K, Specenier P, Pauwels P, Vermorken JB, Peeters $M$, Van Camp G, Baay $M$ and Lardon F: Overcoming cetuximab resistance in HNSCC: the role of AURKB and DUSP proteins. Cancer Lett 354: 365-377, 2014.
65 Azzariti A, Bocci G, Porcelli L, Fioravanti A, Sini P, Simone GM, Quatrale AE, Chiarappa P, Mangia A, Sebastian S, Del Bufalo D, Del Tacca M and Paradiso A: Aurora B kinase inhibitor AZD1152: determinants of action and ability to enhance chemotherapeutics effectiveness in pancreatic and colon cancer. Br J Cancer 104: 769-780, 2011.

66 Payen VL, Porporato PE, Baselet B and Sonveaux P: Metabolic changes associated with tumor metastasis, part 1: tumor $\mathrm{pH}$, glycolysis and the pentose phosphate pathway. Cell Mol Life Sci 73: 1333-1348, 2016.

67 Riganti C, Gazzano E, Polimeni M, Aldieri E and Ghigo D: The pentose phosphate pathway: an antioxidant defence and a crossroad in tumor cell fate. Free Radic Biol Med 53: 421-436, 2012.

68 Osada-Oka M, Hashiba Y, Akiba S, Imaoka S and Sato T: Glucose is necessary for stabilization of hypoxia-inducible factor-1alpha under hypoxia: contribution of the pentose phosphate pathway to the stabilization. FEBS Lett 584: 30733079, 2010.
Received August 15, 2016

Revised September 12, 2016

Accepted September 13, 2016 